\title{
Wash-out kinetics and efficacy of a modified lavage technique for alveolar proteinosis
}

\author{
Francesco Bonella*, Peter C. Bauer*, Matthias Griese*, Thomas E. Wessendorf*, \\ Josune Guzman ${ }^{\top}$ and UIrich Costabel*
}

\begin{abstract}
Whole lung lavage (WLL) is the standard treatment for pulmonary alveolar proteinosis (PAP). This study aimed to provide data about the kinetics of the protein wash-out, to identify factors influencing the protein concentration in the recovered fluid and to assess the efficacy of a modified lavage technique.
\end{abstract}

Samples of 180 WLLs from 42 adult PAP patients were collected. 110 WLLs were performed according to the classical technique. In 70 WLLs, repeated manual ventilation was applied during the procedure. Spectrophotometry was used to measure the protein concentration in the recovered fluid.

The initial protein concentration in the recovered fluid was $460 \mathrm{mg} \cdot \mathrm{dL}^{-1}$, the final concentration was $26 \mathrm{mg} \cdot \mathrm{dL}^{-1}$ and the total amount of removed proteins during a lavage was $17.5 \mathrm{~g}$. A history of dust exposure was associated with a higher residual protein concentration in the recovered fluid $(p=0.000013)$. The amount of removed proteins correlated inversely with the diffusing capacity of the lung for carbon monoxide $(p=0.001)$ and oxygen tension $(p=0.004)$. The modified technique removed a greater amount of proteins than the classical technique and prolonged the time to relapse $(p=0.011)$.

Exposure to dust seems to influence the kinetics of the protein wash-out. Applying manual ventilation during the procedure can enhance the efficacy of WLL.

\section{KEYWORDS: Alveolar proteinosis, modified technique, whole-lung lavage}


ulmonary alveolar proteinosis (PAP), first described in 1958 [1], is a rare syndrome characterised by the intra-alveolar accumulation of surfactant lipids and proteins. PAP can occur in three distinct clinical forms: hereditary, primary autoimmune or idiopathic, and secondary [2-5]. Primary (autoimmune) PAP represents 90\% of PAP cases and is associated with the presence of autoimmune antibodies against granulocyte-macrophage colony stimulating factor (GM-CSF) [6-8]. Secondary PAP occurs as a consequence of several underlying clinical conditions (malignancies, inhalation of toxic agents and immunosuppression) that result in surfactant accumulation [2-5]. Hereditary $\mathrm{PAP}$ is caused by mutations in the GM-CSF receptor gene [6-8].

Whole-lung lavage (WLL), first applied in the late 1960s [9-11], is still the gold standard of therapy [2, 4, 12-19]. This technique has been improved over the years in order to enhance the removal of material from the alveoli [19-23]. Few studies have reported on the protein concentration, the kinetics of the wash-out process and the factors that can influence the biochemical composition of the fluid [15, 24, 25]. PEREZ and Rogers [23] quantified and compared the effective alveolar clearance for each component of the lavage by measuring the dry weight of material in the lavage effluent in five patients. PASCHEN et al. [15] described the kinetics of the wash-out in 10 patients with a total of 45 WLLs and pointed out that monitoring of biochemical variables can help to improve the efficacy of the wash-out. HAMMON et al. [20] compared manual and mechanical percussion in regard to clearance of alveolar material in one PAP patient and concluded that manual percussion is superior to mechanical. BINGISSER et al. [22] showed, in a case study, that manual ventilation between instillation and aspiration during WLL resulted in a persistent functional improvement, but recommended its application only in severely impaired patients, especially when previously performed WLL was ineffective. PEREZ and ROGERS [23] found enhanced alveolar clearance with chest percussion therapy and positional changes during WLL in five patients. There are
AFFILIATIONS

*Dept of Pneumology/Allergy, Ruhrlandklinik and Medical Faculty, University of Duisburg-Essen, Essen, \#Dr von Haunersches Kinderspital, University of Munich, Munich, and -General and Experimental Pathology, Ruhr University, Bochum, Germany.

\section{CORRESPONDENCE}

U. Costabel

Dept of Pneumology/Allergy, Ruhrlandklinik University Hospital Tueschener Weg 4045239 Essen Germany

E-mail: ulrich.costabel@ ruhrlandklinik.uk-essen.de

Received: Jan 282012 Accepted after revision: March 132012

First published online: April 102012 
no large cohort or randomised studies that compare the efficacy of different WLL techniques for PAP.

The present study aimed to provide data about the kinetics of the protein wash-out during WLL, to identify factors influencing the protein concentration in the recovered fluid and to assess the efficacy of a modified lavage technique in a large cohort of patients. Some of the results have been previously reported in the form of an abstract [26].

\section{METHODS}

\section{Study subjects}

This study was conducted at the Ruhrlandklinik (Essen, Germany), a referral centre for the diagnosis and therapy of PAP. The characteristics of the 42 PAP patients (14 males and 28 females) are summarised in table 1 . The study was approved by the local institutional review board (Ethik-Komission der Medizinschen Fakultät der Universität Duisberg-Essen; approval

\section{TABLE 1 Demographics and features of the study cohort}

\begin{tabular}{|c|c|}
\hline Subjects & 42 \\
\hline \multicolumn{2}{|l|}{ Smoking habits at first lavage } \\
\hline Never & 5 \\
\hline Ex-smoker & 20 \\
\hline Current & 17 \\
\hline Previous dust/fume exposure ${ }^{\#}$ & 23 \\
\hline \multicolumn{2}{|l|}{ Pulmonary function at diagnosis } \\
\hline FEV1 \% pred & $73 \pm 15$ \\
\hline FVC \% pred" & $75 \pm 15$ \\
\hline TLC \% pred ${ }^{+}$ & $77 \pm 16$ \\
\hline$D \mathrm{~L}, \mathrm{CO} \%$ pred $^{+}$ & $45 \pm 17$ \\
\hline \multicolumn{2}{|l|}{ Blood gas analysis at diagnosis } \\
\hline $\mathrm{Pa}, \mathrm{O}_{2} \mathrm{mmHg}^{\mathrm{s}}$ & $66 \pm 15$ \\
\hline $\mathrm{Pa}, \mathrm{CO}_{2} \mathrm{mmHg}^{\mathrm{s}}$ & $35 \pm 4$ \\
\hline$(\mathrm{A}-\mathrm{a}) \mathrm{DO}_{2} \mathrm{mmHg}^{\mathrm{s}}$ & $36 \pm 15$ \\
\hline \multicolumn{2}{|l|}{ DSS grade at first lavage } \\
\hline DSS 1 (no symptoms and $\mathrm{Pa}_{1} \mathrm{O}_{2} \geqslant 70 \mathrm{mmHg}$ ) & 0 \\
\hline DSS 2 (symptomatic and $\mathrm{Pa}_{\mathrm{a}_{2}} \mathrm{O}_{2} \geqslant 70 \mathrm{mmHg}$ ) & 14 \\
\hline DSS $3\left(60 \mathrm{mmHg} \leqslant \mathrm{Pa}_{\mathrm{A}_{2}}<70 \mathrm{mmHg}\right)$ & 10 \\
\hline DSS $4\left(50 \mathrm{mmHg} \leqslant{\mathrm{Pa}, \mathrm{O}_{2}}<60 \mathrm{mmHg}\right)$ & 9 \\
\hline DSS $5\left(\mathrm{~Pa}_{1} \mathrm{O}_{2}<50 \mathrm{mmHg}\right)$ & 6 \\
\hline \multicolumn{2}{|l|}{ Serum biomarkers $f$} \\
\hline $\mathrm{GM}-\mathrm{CSF} \mathrm{Ab} \mu \mathrm{g} \cdot \mathrm{mL}^{-1} \# \#$ & $52 \pm 16(28-86)$ \\
\hline $\mathrm{LDH} U \cdot \mathrm{L}^{-1} \oplus$ & $360 \pm 171(126-894)$ \\
\hline CEA $n g \cdot \mathrm{mL}^{-1++}$ & $14 \pm 10(2-27)$ \\
\hline $\mathrm{KL}-6 \mathrm{U} \cdot \mathrm{mL}^{-1 \S \S}$ & $2978 \pm 2488(830-6950)$ \\
\hline
\end{tabular}

Data are presented as $n$, mean $\pm S D$ or mean $\pm S D$ (range). FEV 1 : forced expiratory volume in $1 \mathrm{~s}$; \% pred: \% predicted; FVC: forced vital capacity; TLC: total lung capacity; $\mathrm{DL}, \mathrm{CO}$ : diffusing capacity of the lung for carbon monoxide; $\mathrm{Pa}_{1} \mathrm{O}_{2}$ : arterial oxygen tension; $\mathrm{Pa}_{1} \mathrm{CO}_{2}$ : arterial carbon dioxide tension; $(\mathrm{A}-\mathrm{a}) \mathrm{DO}_{2}$ : alveolar-arterial oxygen delivery; DSS: disease severity score; GM-CSF: granulocyte-macrophage colony stimulating factor; $A b$ : antibody; $L D H$ : lactate dehydrogenase; CEA: carcinoembryonic antigen; KL-6: Krebs von den Lungen-6. ${ }^{\#}$ : aluminum dust, bakery flour dust, cement dust, cleaning products, gasoline fumes, paint, petroleum, sawdust, silica (glass grinding), synthetic plastic fumes or varnish; ${ }^{\bullet}: n=42 ;^{+}: n=38 ;{ }^{\varsigma}: n=39$; ${ }^{f}$ : reference values for serum biomarkers are indicated in the Methods section; ${ }^{\# \#: n=18 ;}{ }^{\bullet}: n=40$; + +t: $n=32 ;{ }^{\S \S}: n=22$. number 06-3170). Informed consent was obtained from the patients.

\section{WLL techniques}

110 WLLs were performed in 33 patients according to the classical lavage technique (CLT) described by RAMIREZ and Coworkers $[9,19]$. 70 WLLs were performed in nine patients with a modification reported by BINGISSER et al. [22] (modified lavage technique (MLT)) (table 2). Most of the patients received consecutive WLLs during the course of their disease.

WLL with both techniques was performed using the same materials (tube and instilled solution) and following the same anaesthesiological protocol (drugs and monitoring procedures). For one complete WLL procedure, both lungs were lavaged separately on two different days. The mean \pm SD interval was $10 \pm 3$ days.

\section{Classical lavage technique}

Patients underwent double-lumen intubation. Ventilation with $100 \%$ oxygen using a volume-controlled ventilator (Servo; Siemens, Danvers, MA, USA) was started. An indwelling arterial catheter was placed. The tube was tested for leaks by single-lung ventilation. A flexible fibreoptic bronchoscope was used to ascertain the proper tube position initially and during the procedure. The lung to be washed was clamped for $5 \mathrm{~min}$ to allow oxygen absorption. Saline solution at body temperature was instilled into the non-ventilated lung with a tidal washing volume of $1,000 \pm 200 \mathrm{~mL}$ during each cycle. After recovering the opaque fluid through a closed silicone tube system, the next washing cycle was begun. The optical density (OD) was measured in each recovered tidal volume to monitor the progress of the lavage procedure [15]. The recovery rate of each cycle was accurately documented. The lavage cycles were continued until the OD reached the target value of $<0.4$, or

\begin{tabular}{|c|c|c|c|c|}
\hline \multirow[t]{2}{*}{ TABLE 2} & \multicolumn{4}{|c|}{$\begin{array}{l}\text { Allocation of the patients and patients' features } \\
\text { according to whole-lung lavage (WLL) } \\
\text { techniques }\end{array}$} \\
\hline & & CLT & MLT & p-value \\
\hline \multicolumn{2}{|l|}{ Patients } & 33 & 9 & \\
\hline \multicolumn{2}{|c|}{ Males/females } & $23 / 10$ & $5 / 4$ & NS \\
\hline \multicolumn{2}{|l|}{ Age yrs } & $44 \pm 11$ & $43 \pm 9$ & NS \\
\hline \multicolumn{2}{|l|}{$\mathrm{BMI} \mathbf{k g} \cdot \mathrm{m}^{-2}$} & $25 \pm 4$ & $25 \pm 5$ & NS \\
\hline \multicolumn{2}{|c|}{ Current smokers } & 14 & 3 & NS \\
\hline \multicolumn{2}{|c|}{ Previous dust/fumes exposure } & 20 & 3 & NS \\
\hline \multicolumn{2}{|l|}{ TLC \% pred } & $77 \pm 10$ & $77 \pm 27$ & NS \\
\hline \multicolumn{2}{|l|}{ DL,Co \% pred } & $48 \pm 20$ & $41 \pm 10$ & NS \\
\hline \multicolumn{2}{|l|}{$\mathrm{Pa}, \mathrm{O}_{2} \mathrm{mmHg}$} & $65 \pm 15$ & $69 \pm 18$ & NS \\
\hline \multicolumn{2}{|c|}{ Time from diagnosis to first WLL days } & $530(5-3691)$ & $261(5-876)$ & NS \\
\hline \multicolumn{2}{|c|}{ Lavaged lung right/left } & $55 / 55$ & $33 / 37$ & \\
\hline
\end{tabular}

Data are presented as $n$, mean \pm SD or median (range), unless otherwise stated CLT: classical lavage technique; MLT: modified lavage technique; BMI: body mass index; TLC: total lung capacity; \% pred: \% predicted; DL,CO: diffusing capacity of the lung for carbon monoxide; $\mathrm{Pa}_{1} \mathrm{O}_{2}$ : arterial oxygen tension; NS: not significant. 
until a plateau was reached. In general, 30-60 L were needed to achieve this.

\section{Modified lavage technique}

The intubation procedure and the infusion-recovery cycle at the beginning of the lavage procedure were the same as for the CLT. When the target OD value of $<0.4$ was reached with the classical procedure, controlled manual ventilation was applied during one infusion-recovery cycle as follows: at first, $500 \mathrm{~mL}$ of saline solution was instilled and then the ventilation was started. A tidal volume of $300 \mathrm{~mL}$ of room air was delivered by the bag five times consecutively, without fluctuations. After having recovered the first $500 \mathrm{~mL}$ of instilled saline solution, the rest of the fluid $(500 \mathrm{~mL})$ of this cycle was instilled and recovered, and the next cycle was started. Subsequently, the lavage was continued until the target $\mathrm{OD}$ value $<0.4$ was reached for the second time.

\section{Laboratory measurements}

\section{GM-CSF autoantibody in serum}

GM-CSF autoantibody concentration was measured by ELISA as previously reported $[27,28]$. The detection limit of our assay is $0.2 \mu \mathrm{g} \cdot \mathrm{mL}^{-1}$. Values $<10 \mu \mathrm{g} \cdot \mathrm{mL}^{-1}$ are considered normal.

\section{Biomarkers in serum and bronchoalveolar lavage}

KL-6 was measured by ELISA (Eisai Co. Ltd, Tokyo, Japan) as described previously [29] in serum and bronchoalveolar lavage (BAL). Lactate dehydrogenase (LDH) and carcinoembryonic antigen (CEA) were measured in serum only. Normal serum ranges in our laboratory are: $<620 \mathrm{U} \cdot \mathrm{mL}^{-1}$ for $\mathrm{KL}-6,<200 \mathrm{IU} \cdot \mathrm{L}^{-1}$ for $\mathrm{LDH}$ and $<2.5 \mathrm{ng} \cdot \mathrm{mL}^{-1}$ for CEA.

\section{Rapid turbidity assessment}

The OD of the recovered fluid was measured at a wavelength of 405 nm (EPAC 6140; Eppendorf, Hamburg, Germany).

\section{Protein concentration}

The recovered fluid was centrifuged at $1,720 \times \mathrm{g}$ for $10 \mathrm{~min}$ in order to separate water-insoluble particulate materials including cells and debris, as described by ONODERA et al. [24]. In the supernatant, the total protein concentration was measured with a spectrophotometer in standardised volumes $(10 \mathrm{~mL})$ and in duplicate (Konelab T series for U/CSF protein; Thermo Fisher Scientific, Vantaa, Finland).

\section{Statistics}

All variables were evaluated for a normal distribution using the Kolmogorov-Smirnov test and for equal variance using the Levene median test. The area under the curve (AUC) was calculated by the trapezoidal method and verified with the integration of regression equation. The following variables had no normal distribution: disease severity score (DSS), volume of instilled fluid, protein concentration and amount of removed proteins (AUC). Therefore, these variables are expressed as median (50th percentile) and interquartile range. Categorical data are presented as either a percentage of the total or numerically, as appropriate. Statistical comparisons of parametric data were made with t-test for two group comparisons. Nonparametric data were compared using the Wilcoxon test. Comparisons of categorical data were made with the Chisquared test or Fisher's exact test. Longitudinal data of parametric data (biomarkers and lung function tests) were compared using the paired t-test. The comparison of the means in the same subjects at different times was performed with oneway repeated measures ANOVA, and the comparison of repeated measures between the techniques (MLT versus CLT) using a general linear model for repeated measures. Spearman's or Pearson's coefficient was obtained for all correlations. Partial correlation analysis (with covariates) and regression analysis were used to confirm the correlations. All tests were two sided and p-values of $<0.05$ were considered statistically significant.

\section{RESULTS}

There was a linear correlation between the protein concentration determined with the quantitative method (Konelab) and the OD (fig. 1).

\section{Kinetics of the wash-out process}

Protein concentration

The median protein concentration in the first portion of the recovered fluid of $180 \mathrm{WLLs}$ was $460 \mathrm{mg} \cdot \mathrm{dL}^{-1}\left(15-3,907 \mathrm{mg} \cdot \mathrm{dL}^{-1}\right)$. There was no correlation of this initial protein concentration with age, body mass index (BMI) or smoking habits. An inverse correlation was seen with total lung capacity (TLC) $(n=126$; $\mathrm{r}=-0.222, \mathrm{p}=0.012)$ and arterial oxygen tension $\left(\mathrm{Pa}_{\mathrm{a}} \mathrm{O}_{2}\right)(\mathrm{n}=142$; $\mathrm{r}=-0.214, \mathrm{p}=0.01)$. The initial protein concentration correlated with the DSS $(n=142 ; r=0.3, p=0.002)$, the duration of disease $(\mathrm{n}=180 ; \mathrm{r}=-0.4, \mathrm{p}=0.012)$ and the time interval from diagnosis to first treatment $(n=180 ; r=-0.3, p=0.015)$. There was also a correlation with serum LDH $(n=149 ; \mathrm{r}=0.5, \mathrm{p}=0.0001)$ and BAL fluid KL-6 concentration $(n=26 ; r=0.44, p=0.02)$. No correlations were found with serum CEA or GM-CSF autoantibody levels.

The median protein concentration in the final portion of the recovered fluid was $26(4-71) \mathrm{mg} \cdot \mathrm{dL}^{-1}$.

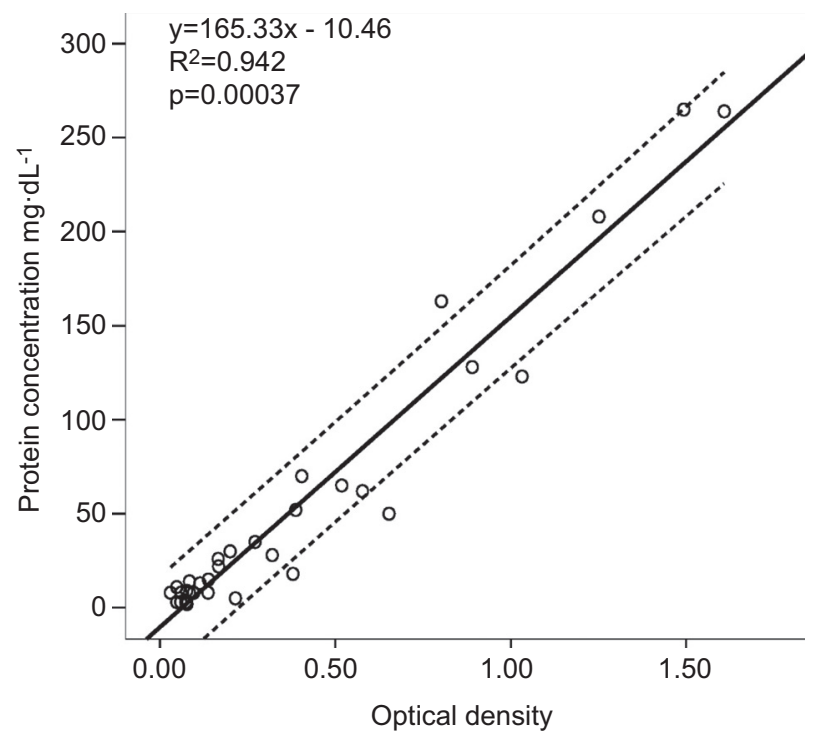

FIGURE 1. Regression curve fit showing the linear correlation (bold line) between the protein concentration (assessed by Konelab quantitative analysis) and the optical density of the spectrophotometric absorption in the first recovered portion of six consecutive whole lung lavages. Linear equations with 95\% confidence intervals (dashed lines), the correlation coefficient and the significance are also shown. 

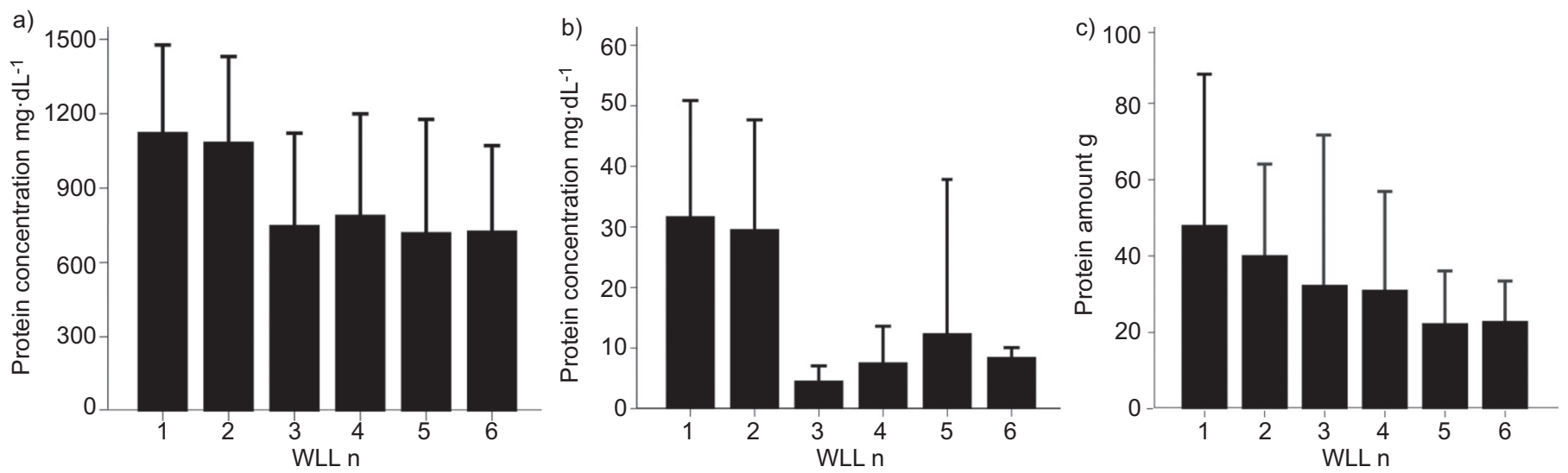

FIGURE 2. Change of protein wash-out kinetics in nine patients who underwent six consecutive whole lung lavages (WLL). a) Initial protein concentration, b) final protein concentration, and c) protein amount.

\section{Protein amount}

The median amount of proteins removed from the lung by one WLL was $17.5 \mathrm{~g}(7.2-41 \mathrm{~g})$. This was not affected by sex, age, BMI, the WLL being performed in the left or right lung, smoking habits or a history of dust exposure (data not shown).

The removed protein amount correlated inversely with diffusing capacity of the lung for carbon monoxide $(n=54 ; r=-0.44$, $\mathrm{p}=0.001)$ and $\mathrm{Pa}_{2} \mathrm{O}_{2}(\mathrm{n}=142 ; \mathrm{r}=-0.243, \mathrm{p}=0.004)$, and directly with the DSS $(n=142 ; r=0.3, p=0.0001)$, serum LDH $(n=149$; $r=0.53, p=0.0001)$ and BAL KL-6 levels $(n=26 ; r=0.533$, $p=0.005$ ). No correlations were found with serum KL-6, CEA or GM-CSF antibodies.

\section{Other results}

The protein concentration in the last recovered portion was higher in patients exposed to dust/fumes than in those not exposed, with a median value of $24(9-57) \mathrm{mg} \cdot \mathrm{dL}^{-1}$ versus 9 $(3-21) \mathrm{mg} \cdot \mathrm{dL}^{-1} \quad(\mathrm{p}=0.00013)$; the instilled volume per WLL between the two groups did not differ (25 (16-32) L versus 27 (20-34) L; $\mathrm{p}=0.08)$ and was not considered as a covariate.

Nine patients underwent six consecutive WLLs. Six patients received CLT and three patients MLT. The mean interval between multiple WLLs in this subgroup of nine patients that were lavaged six times was $138 \pm 105$ days. The initial protein concentration in the recovered fluid did not change significantly from the first to the last WLL (fig. 2a), but the final protein concentration significantly decreased with the third WLL $(p=0.048)$ (fig. $2 b)$. The amount of removed protein declined with consecutive WLLs $(p=0.04)$ (fig. $2 c)$ but the instilled volume did not change $(p=0.2)$ (data not shown).

\section{Comparison of the WLL techniques}

The results from the comparison of the WLL techniques are summarised in table 3. The patients who received MLT had a significantly lower final protein concentration (median 9 (3-20) $\mathrm{mg} \cdot \mathrm{dL}^{-1}$ ) than those receiving CLT (median 22 $\left.(5-58) \mathrm{mg} \cdot \mathrm{dL}^{-1} ; \mathrm{p}=0.00016\right)$.

In patients undergoing up to six consecutive WLLs, the instilled volume necessary to reach the target final protein concentration remained higher for MLT than CLT. A tendency to decline was only shown with the application of repeated MLTs (fig. 3).

There was an inverse correlation between the final protein concentration and the total volume instilled $(\mathrm{r}=-0.257$, $\mathrm{p}=0.00049$ ). When corrected for volume, the difference in the final protein concentration between the two techniques still remained significant $(\mathrm{p}=0.001)$.

TABLE 3 Results from the comparison of whole-lung lavage techniques

\begin{tabular}{|c|c|c|c|}
\hline Instilled volume $\mathbf{L}$ & $15(4-40)(n=110)$ & $40(21-71)(n=70)$ & $0.0003^{\#}$ \\
\hline Final protein concentration $\mathrm{mg} \cdot \mathrm{dL}^{-1}$ & $21(1-593)(n=110)$ & $9(1-39)(n=70)$ & $0.0002^{\#}$ \\
\hline Amount of removed protein $\mathrm{mg}$ & $13780(350-32015)(n=110)$ & $22580(2920-26860)(n=70)$ & $0.0001^{\#}$ \\
\hline Time range 1 st-2nd WLL days & $84 \pm 168(n=29)$ & $225 \pm 151(n=9)$ & $0.011^{\circ}$ \\
\hline WLLs per patient & $3.2 \pm 2$ & $4.2 \pm 5$ & NS ${ }^{*}$ \\
\hline
\end{tabular}




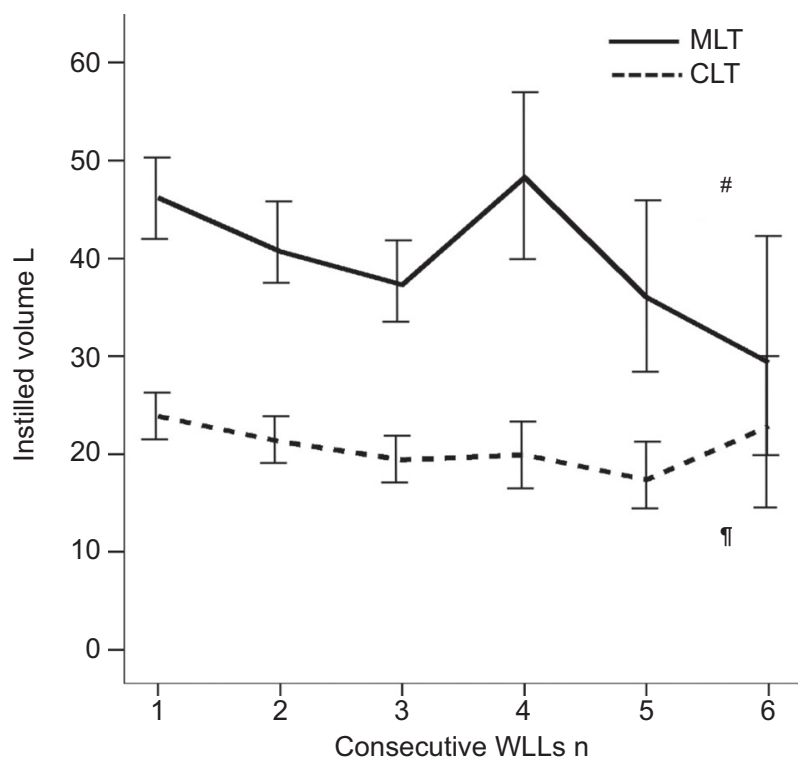

Patients $n$

\begin{tabular}{lcccccc} 
MLT & 9 & 14 & 5 & 6 & 4 & 3 \\
\hline & 33 & 27 & 15 & 12 & 11 & 6
\end{tabular}

FIGURE 3. Mean instilled volume in up to six consecutive whole lung lavages (WLLs), according to the applied technique. Error bars indicate 95\% confidence intervals. p-values refer to significance for the comparison in each group (ANOVA). The difference between groups remained significant in each measure (overall $p=0.044$ ) (general linear model test between subjects). MLT: modified lavage technique; CLT: classic lavage technique. ${ }^{\#}: p=0.13 ; " ; p=0.32$.

Figure 4 shows the effect of manual ventilation on the protein wash-out. The amount of removed proteins, represented by the AUC in figure 4, was significantly greater with MLT than with the CLT (table 3). The volume instilled and recovered through
CLT did not exceed $40 \mathrm{~L}$, while the volume with MLT reached up to $71 \mathrm{~L}$ in one session, which is the reason why more material was removed with this technique. When corrected for volume, the difference in the amount of removed proteins between CLT and MLT was no longer significant $(p=0.121)$.

\section{DISCUSSION}

Since its introduction by RAMIREZ et al. [9], WASSERMAN et al. [10] and SEARD et al. [11], WLL is still the treatment of choice in patients with PAP $[2,4,12-18]$. In this study, we provide detailed data on kinetics of protein wash-out in the recovered fluid (initial and final protein concentration, and amount of removed proteins) of 180 WLL procedures in a cohort of 42 adult PAP patients. We also compared the wash-out efficacy of two different lavage techniques. To the best of our knowledge, this is the largest single-centre study regarding WLL reported worldwide.

In our PAP cohort, we observed an exponential decay of the protein concentration during the lavage, similar to data published before [21, 23, 24, 30]: the median initial protein concentration was at least 20 -fold higher than the final concentration. We did not find a correlation with age, BMI or side lavaged. The initial value of the protein concentration showed an inverse correlation with TLC $(\mathrm{p}=0.012), \mathrm{Pa}_{1} \mathrm{O}_{2}(\mathrm{p}=0.01)$ and a direct correlation with the DSS ( $p=0.002)$. This may be explained by the degree of filling of the alveolar space. The correlation between the initial protein concentration and the time from diagnosis to first WLL $(p=0.015)$ seems to indicate that the abnormal lipoprotein burden of the lungs increases over time. Furthermore, the observed correlation between the initial protein concentration, duration of disease and well established biomarkers for PAP (serum LDH and BAL KL-6 levels) [31, 32] suggests that also the initial protein concentration could have a role as biomarker.

The median protein concentration of $26 \mathrm{mg} \cdot \mathrm{dL}^{-1}$ at the end of the lavage is consistent with that reported by PASCHEN et al. [15]

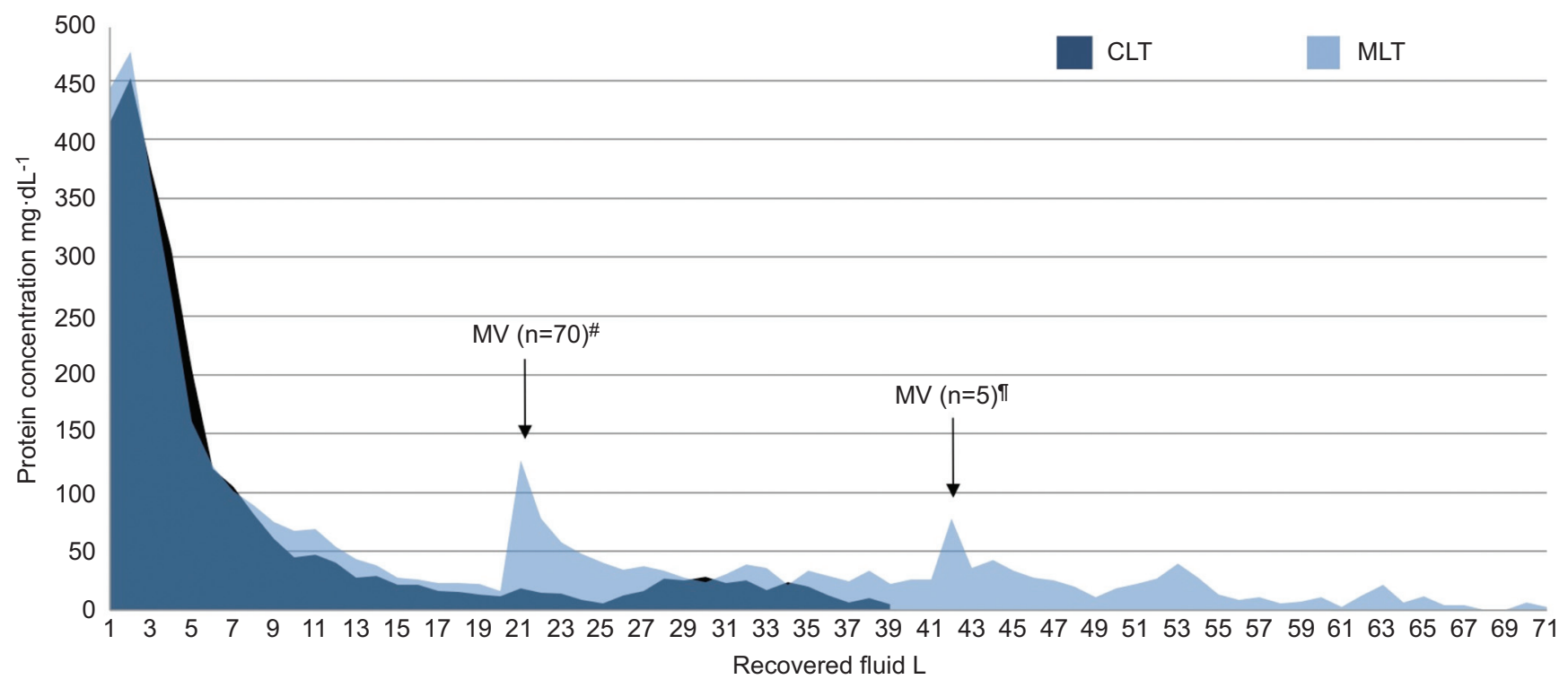

FIGURE 4. Comparison between the classical (CLT) ( $n=110$ procedures) and the modified (MLT) lavage technique ( $n=70$ procedures) in removing proteins from the lung. The amount of removed proteins is represented by the area under the curve. The arrows indicate when the manual ventilation (MV) was applied during the procedure, mostly after $21 \mathrm{~L}$ and $41 \mathrm{~L}$. Statistics are described in the main text. ${ }^{*}$ : in 70 whole lung lavage (WLL) procedures, MV was applied only once during the procedure; ": in five WLL procedures, MV was applied twice during the procedure. 
$\left(10 \mathrm{mg} \cdot \mathrm{dL}^{-1}\right)$ and by ALBERTI et al. [25] $\left(20-80 \mathrm{mg} \cdot \mathrm{dL}^{-1}\right)$. The amount of protein removed from the lungs $(17.5 \mathrm{~g})$ was compatible with the range reported by PASCHEN et al. [15] (2-33 g) and by CERUTI et al. [33] (6.5-8.5 g), and was not affected by sex, age, BMI, dust exposure or smoking habits.

Moreover, we found that a history of dust exposure, but not smoking, was associated with a higher residual protein concentration in the recovered fluid. This needs further investigation because the protein concentration in the first recovered portion only shows a tendency to be higher in patients exposed to dusts and fumes.

The effect of consecutive WLLs on the protein kinetics has not been investigated before. We found a progressive decline in the amount of removed protein and a better clearance with consecutive procedures.

Finally, we showed that a modified WLL technique with manual ventilation can remove a larger amount of protein and reduce the residual protein concentration in the fluid more than the classical technique described by RAMIREZ et al. [9]. The amount of proteins removable from the lungs depends on the instilled volume. The manual ventilation in the middle of the procedure seems to mobilise additional proteins from the alveoli. The magnitude of the second protein concentration peak (after manual ventilation) was about one-third of the initial (fig. 3); then, the wash-out curve declined as usual. An ideal technique of WLL should remove the largest amount of protein with the smallest instilled volume, in order to reduce the duration of anaesthesia and the risk of complications, like overspill of lavage fluid into the ventilated lung, barotrauma, hydropneumothorax and severe acidosis [18]. Even if MLT is not the ideal lavage technique, it seems to be more effective in prolonging the time to the second WLL compared to the classical technique (table 3).

There are several limitations of this study. First, there is an imbalance in the number of patients assigned to the different techniques. Secondly, we did not perform systematically gel electrophoresis/Western blot analysis to separate the proteins; therefore, we cannot exclude an influence of aberrant lipoproteins on the kinetics of the procedure.

In summary, this study supports the concept that the kinetics of protein removal from the lungs can be easily estimated by spectrophotometry of the effluent and can provide biochemical variables of clinical interest for the outcome. The clearance of the fluid through WLL appears be affected by a history of dust exposure, but not by smoking. Applying manual ventilation during the procedure can enhance the efficacy of WLL, even if it does not reduce the volume to be instilled.

\section{SUPPORT STATEMENT}

This study was supported by the German Federal Ministry of Education and Research (EuPAPNet project, number 01GM1011A) and Arbeitsgemeinschaft zur Förderung der Pneumologie an der Ruhrlandklinik.

\section{STATEMENT OF INTEREST}

None declared.

\section{REFERENCES}

1 Rosen SH, Castleman B, Liebow AA. Pulmonary alveolar proteinosis. N Engl J Med 1958; 258: 1123-1142.
2 Seymour JF, Presneill JJ. Pulmonary alveolar proteinosis: progress in the first 44 years. Am J Respir Crit Care Med 2002; 166: 215-235.

3 Inoue $\mathrm{Y}$, Trapnell BC, Tazawa $\mathrm{R}$, et al. Characteristics of a large cohort of patients with autoimmune pulmonary alveolar proteinosis in Japan. Am J Respir Crit Care Med 2008; 177: 752-762.

4 Trapnell BC, Whitsett JA, Nakata K. Pulmonary alveolar proteinosis. N Engl J Med 2003; 349: 2527-2539.

5 Huizar I, Kavuru MS. Alveolar proteinosis syndrome: pathogenesis, diagnosis, and management. Curr Opin Pulm Med 2009; 15: 491-498.

6 Carey B, Trapnell BC. The molecular basis of pulmonary alveolar proteinosis. Clin Immunol 2010; 135: 223-235.

7 Kitamura T, Tanaka N, Watanabe J, et al. Idiopathic pulmonary alveolar proteinosis as an autoimmune disease with neutralizing antibody against granulocyte/macrophage colony-stimulating factor. J Exp Med 1999; 190: 875-880.

8 Costabel U, Guzman J. Pulmonary alveolar proteinosis: a new autoimmune disease. Sarcoidosis Vasc Diffuse Lung Dis 2005; 22: Suppl. 1, S67-S73.

9 Ramirez J, Schultz RB, Dutton RE. Pulmonary alveolar proteinosis: a new technique and rationale for treatment. Arch Intern Med 1963; 112: 419-431.

10 Wasserman K, Blank N, Fletcher G. Lung lavage (alveolar washing) in alveolar proteinosis. Am J Med 1968; 44: 611-617.

11 Seard C, Wasserman K, Benfield JR, et al. Simultaneous bilateral lung lavage (alveolar washing) using partial cardiopulmonary bypass. Am Rev Respir Dis 1970; 101: 877-884.

12 Selecky PA, Wasserman K, Benfield JR, et al. The clinical and physiological effect of whole-lung lavage in pulmonary alveolar proteinosis: a ten-year experience. Ann Thorac Surg 1977; 24: 451-461.

13 Kavuru MS, Popovich M. Therapeutic whole lung lavage: a stopgap therapy for alveolar proteinosis. Chest 2002; 122: 1123-1124.

14 Morgan $C$ The benefits of whole lung lavage in pulmonary alveolar proteinosis, Eur Respir J 2004; 23: 503-505.

15 Paschen C, Reiter K, Stanzel F, et al. Therapeutic lung lavages in children and adults. Respir Res 2005; 6: 138.

16 Cheng SL, Chang HT, Lau HP, et al. Pulmonary alveolar proteinosis: treatment by bronchofiberscopic lobar lavage. Chest 2002; 122: 1480-1485.

17 Ioachimescu OC, Kavuru MS. Pulmonary alveolar proteinosis. Chron Respir Dis 2006; 3: 149-159.

18 Shah PL, Hansell D, Lawson PR, et al. Pulmonary alveolar proteinosis: clinical aspects and current concepts on pathogenesis. Thorax 2000; 55: 67-77.

19 Ramirez J. Bronchopulmonary lavage. New techniques and observations. Dis Chest 1966; 50: 581-588.

20 Hammon WE, McCaffree DR, Cucchiara AJ. A comparison of manual to mechanical chest percussion for clearance of alveolar material in patients with pulmonary alveolar proteinosis (phospholipidosis). Chest 1993; 103: 1409-1412.

21 Rodi G, Iotti G, Galbusera C, et al. Whole lung lavage. Monaldi Arch Chest Dis 1995; 50: 64-66.

22 Bingisser R, Kaplan V, Zollinger A, et al. Whole-lung lavage in alveolar proteinosis by a modified lavage technique. Chest 1998; 113: 1718-1719.

23 Perez A, Rogers RM. Enhanced alveolar clearance with chest percussion therapy and positional changes during whole-lung lavage for alveolar proteinosis. Chest 2004; 125: 2351-2356.

24 Onodera T, Nakamura M, Sato T, et al. Biochemical characterization of pulmonary washings of patients with alveolar proteinosis, interstitial pneumonitis and alveolar cell carcinoma. Tohoku J Exp Med 1983; 139: 245-263.

25 Alberti A, Luisetti M, Braschi A, et al. Bronchoalveolar lavage fluid composition in alveolar proteinosis. Early changes after therapeutic lavage. Am J Respir Crit Care Med 1996; 154: 817-820.

26 Bonella FCM, Ohshimo S, Bavee PC, et al. Determinants of protein concentration in whole lung lavage of patients with pulmonary alveolar proteinosis. Eur Respir J 2009; 34: A4674. 
27 Latzin $\mathrm{P}$, Tredano M, Wust $\mathrm{Y}$, et al. Anti-GM-CSF antibodies in paediatric pulmonary alveolar proteinosis. Thorax 2005; 60: 39-44.

28 Uchida K, Nakata K, Suzuki T, et al. Granulocyte/macrophage colony-stimulating factor autoantibodies and myeloid cell immune functions in healthy subjects. Blood 2009; 113: 2547-2456.

29 Takahashi T, Munakata M, Suzuki I, et al. Serum and bronchoalveolar fluid KL-6 levels in patients with pulmonary alveolar proteinosis. Am J Respir Crit Care Med 1998; 158: 1294-1298.

30 Beccaria M, Luisetti M, Rodi G, et al. Long-term durable benefit after whole lung lavage in pulmonary alveolar proteinosis. Eur Respir J 2004; 23: 526-531.
31 Seymour JF, Doyle IR, Nakata K, et al. Relationship of anti-GMCSF antibody concentration, surfactant protein A and B levels, and serum LDH to pulmonary parameters and response to GM-CSF therapy in patients with idiopathic alveolar proteinosis. Thorax 2003; 58: 252-257.

32 Lin FC, Chen YC, Chang SC. Clinical importance of bronchoalveolar lavage fluid and blood cytokines, surfactant protein $\mathrm{D}$, and Kerbs von Lungren 6 antigen in idiopathic pulmonary alveolar proteinosis. Mayo Clin Proc 2008; 83: 1344-1349.

33 Ceruti M, Rodi G, Stella GM, et al. Successful whole lung lavage in pulmonary alveolar proteinosis secondary to lysinuric protein intolerance: a case report. Orphanet J Rare Dis 2007; 2: 14. 